\title{
Management of Urethrocutaneous Fistula Following Circumcision in Mbour Hospital, Senegal
}

\author{
Kouka SCN*, Diallo Y*, Yonga D**, Ouaimon DS **, Jalloh $\mathrm{M}^{* * *}$, Diop C*, Ndiaye MD*, LY R*, Sylla C* \\ * Department of Urology, Faculty of Health Sciences, University of Thies, SENEGAL. \\ ** Service of Surgery, County Hospital in Mbour, SENEGAL. \\ ***Department of Urology, University Cheikh Anta Diop of Dakar, SENEGAL. \\ saintkouka@yahoo.fr \\ *Corresponding Author: Kouka SCN, Department of Urology, Faculty of Health Sciences, University of Thies, Senegal.
}

\begin{abstract}
Purpose: We report the epidemiological, clinical and therapeutic aspects of Urethrocutaneous fistula which is an unusual but preventable complication following circumcision.
\end{abstract}

Materials and Methods: We carried out a retrospective and descriptive study, of all children who presented with urethrocutaneous fistula following circumcision over a period of 7 years,from March 2012 to February 2018.

Results: Eighteen patients ( $n=18$ ) with Urethrocutaneous fistulas (UCF) following circumcision were treated in Mbour hospital (Senegal). The mean age was 6.61 years (Range: 2; 14 years). The mean consultation time in a specialized setting was 20 months (Range: 3 months; 2 years). The circumcision was performed by a nonphysician health professional in 14 cases and by a traditional practitioner in 4 cases. Sixteen patients underwent an urethro-skin closure by the suture in two distinct lines. We made a broad-base skin flap for one patient and used Davis method for one case. All patients were admitted for 5 days and then followed up at 1 week, 1 month and 3 months. The therapeutic results were satisfactory in $88.88 \%(n=16)$ of the cases after a follow-up of 1 year. Two cases of fistula recurrence was recorded and they were treated successfully.

Conclusions: Urethrocutaneous fistula following circumcision is frequently seen in our surgical practice. Its prevention requiresthe respect and control of the different stages of circumcision, but also education and training of healthcare professional performing the circumcision.

Keywords: urethrocutaneous fistula, Circumcision, complication, Senegal

\section{INTRODUCTION}

Circumcision is the most common operation performed in the world for mainly cultural and religious reasons[1]. It is a minor surgical procedure often performed by non-expert hands.In sub-Saharan Africa especially in Senegal $[2,3,7,8]$, several complications have been reported following circumcision in children (glans amputation, hemorrhage, urethral stenosis or meatus stenosis, urethrocutaneous fistula, suppurations). The aim of our study was to analyze the anatomic, clinical and therapeutic aspects of urethrocutaneous fistulas following circumcision and their management in our daily urological practice.

\section{Patients AND Methods}

We carried out a retrospective and descriptive study, of all children who presented with urethrocutaneous fistulas following circumcision over a period of 7 years from March 2012 to February 2018. The patients included in this study were all referred to the urology department of Grand Mbour Hospital with complete medical record, operative report, post-operative follow-up of at least for three months. We excluded any patient who did not have a full medical record or who refused the therapeutic offer.

The variables studied were age, time to consultation, circumstances of occurrence (level of qualification 
of the staff), clinical finding, surgical treatment and outcome. A blood cell count, urine culture and serum creatinine measure were performed systematically in all patients. Medical Treatment were antibiotics, analgesics, non-steroidal anti-inflammatory drugs. Surgery was performed in an operating theatre under general anesthesia.

An elliptical skin incision circumscribing the fistula was made, excising the fibrous tissues, then a skin flap was developed to cover the fistula by a two lines suture making sure the suture lines were not superposed (urethra, then skin). In a large fistula a broad-based skin flap (penile skin) was fashioned for fistula closure. Davis method which consists of an endourethral suture of the fistula by $4 / 0$ absorbable suture was used. Foley catheter were inserted to drain the bladder. The patients were instructed to return for follow up at seven days, one month and two months post surgery.

Data were analyzed using Microsoft Office Word and Excel version 2007 software.

Free and informed consent had been obtained regarding the use of the data collected and the images taken for the purposes of medical publication.

\section{RESULTS}

Between February 2012 and June 2018, sixty-five patients were referred for complication of circumcision. This included 18 cases with Urethrocutaneous fistulas (UCF) treated in the urology-andrology department of Grand Mbour hospital, accounting for $31.11 \%$ of all complications. The mean age was 6.61 years (Range: $2 ; 14$ years). Table 1 summarizes the clinical characteristics and therapeutic aspectsof the 18 patients. The 6-10 years age group was the mostrepresented.

The mean consultation time in a specialized setting was 20 months (Range: 3 months; 2 years). The circumcision was performed by a non-physician healthcare professional in 14 cases and by a traditional practitioner in 4 cases. The UCF was located in all cases at the level of the neck of the glans on the ventral side of the penis. The functional symptomatology was dominated by urination through two openings (Figure 1). Regarding the topography of the fistula, it was in all cases at the level of the glans neck on the ventral side of the penis with a variable size. Blood cell count, urine culture and serum creatinine were normal in all patients. Sixteen patients were treated by a dissection of the fistula and suture in two distinct lines. We made a broad-based skin flap for one patient and used Davis method for one case. All patients were hospitalized for 5 days and then seen again at 1 week, 1 month and 3 months.

The therapeutic results were satisfactory in $88.88 \%$ $(n=16)$ of the cases after a follow-up of 1 year. These results were assessed according to the following criteria: the absence of urine leakage;agood urinary stream by the urethral meatus without difficulty and satisfactory cosmetic aspect of the penis. Two cases offistula recurrence were recorded and they were treated successfully.

Table1. Clinicalcharacteristicsand therapeutic aspects of patients withpostcircumcision urethrocutaneous fistula

\begin{tabular}{|c|c|c|c|}
\hline Variables & & Frequency & $(\%)$ \\
\hline & Total patients & 18 & 100 \\
\hline Age group & $1-5$ years & 7 & 38,90 \\
\hline & $6-10$ years & 8 & 44,45 \\
\hline Circumcisers & $11-15$ years & 3 & 1,65 \\
\hline & Paramedical agent & 14 & 77,77 \\
\hline Fistulasurgery & Traditionalpractitioner & 4 & 22,23 \\
\hline & suture in two distinct lines & 16 & 88.88 \\
\hline & broad-based skin flap & 1 & 5,56 \\
\hline
\end{tabular}




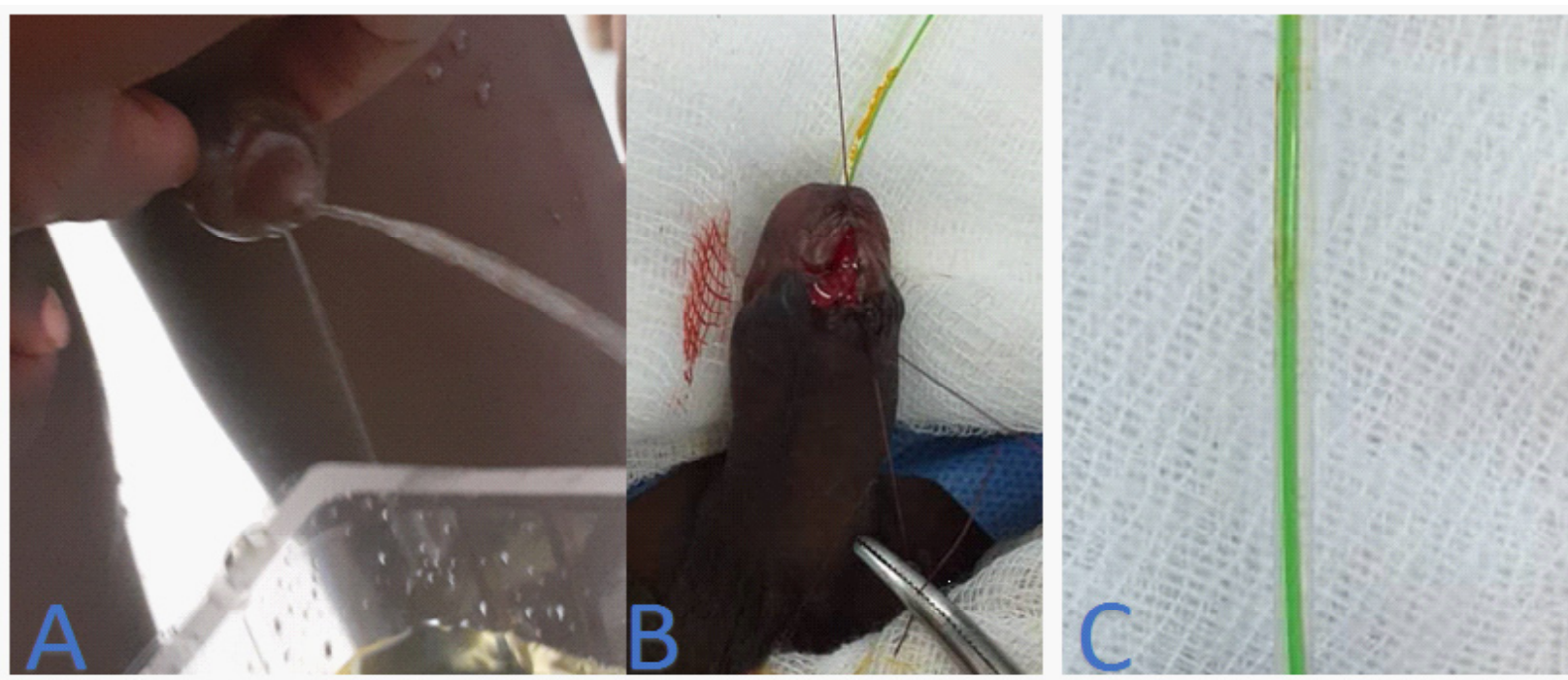

Figure 1. (A) Urination through two openings, $(\boldsymbol{B}, \boldsymbol{C})$ Small coronal urethrocutaneous fistulatreated by two lines suture withurethralstent

\section{DISCUSSION}

Circumcision is a surgical procedure, which can result in distressing complications including urethrocutaneous fistula (UCF). In Senegal, it is most often carried out by various operators, qualified or not $[2,4,5]$. Sylla [2] and Sow [5] respectively reported 41 and 85 cases of UFC following circumcision.If the penile fistula seems to be particularly favored by circumcision done in a traditional way [2, 4]. Inour series and in that of Sow [5] the majority of them were consecutive to a circumcision made bynon-physician healthcare professional and unqualified individuals respectively in $73.7 \%$ and $55.3 \%$ of cases.

The mean age was 6.61 years (Range: $2 ; 14$ years). This finding is consistent with the findings of other African authors $[5,8]$. This variability in age can be explained by the fact that circumcision can be performed at any age in African societies, given the diversity of populations and traditions. However, the prophylactic effects of circumcision performed in the neonatal period are well known [7]. The mean time of consultation in urological environment although long in our series (18 months) remains lower than that of Ba et al [4] who reported a mean time of 2 and 8 years. UFC would occur during a urethral wound caused by non-elective hemostasis of the artery $[2,8]$ in the surgical method of circumcision or during ventral preputial section in the traditional method of circumcision [10].

From a therapeutic point, surgery was required and consisted of 2separated lines of suturesas performed by several authors [2,5,8]. Ba et al [4] preferred the Davis method. For Baskin et al. [11], reversal skin flap was only carried out in large fistulas. The drainage by urethral catheterization was systematic in our series. However it is not essential especially when it is a small fistula. Some authors [2, 5, 9] believe that the urethral catheter could be a risk factor for failure of fistula repair because of the infectious risk it generates, especially when it is kept for a long time.

\section{Conclusion}

The penile fistula is a significant complication of circumcision. Its prevention requires respect and control of the different stages of circumcision.

\section{REFERENCES}

[1] Lackey JT, Mannion RA, Kerr JE. Urethral fistula following circumcision. JAMA 1968;206:2318.

[2] Sylla C, Diao B, Diallo AB, Fall PA, Sankale AA, Ba M. Les complications de la circoncision. A propos de 63 cas. Prog.Urol. 2003;13(2):266-72.

[3] Appiah KA, Gyasi-Sarpong CK, Azorliade R, Aboah K, Laryea DO, Otu-Boateng K, et al. Circumcision-related tragedies seen in children at the KomfoAnokye Teaching Hospital, Kumasi, Ghana. BMC Urology. 2016;16(1):65.

[4] Ba M, Ndoye A, Fall PA, Sylla C, Gueye SM, Diagne BA. Penile urethral fistula after circumcision. Andrologie. 2000;10(1):75-7. 
Management of Urethrocutaneous Fistula Following Circumcision in Mbour Hospital, Senegal

[5] Sow Y, Diao B, Tfeil YO et al. Les fistules péniennes urétro-cutanées post circoncision. Andrologie.2009;19: 99-102.

[6] Aaron A. R. Tobian, Ronald H. Gray. The Medical Benefits of Male Circumcision. JAMA 2011;306(13):1479-80.

[7] Ikuerowo SO, Bioku MJ, Omisanjo OA, Esho JO. Urethrocutaneous fistula complicating circumcision in children. Niger J Clin Pract 2014;17:145-8.

[8] Diallo AB, Touré A, Diallo TMO , Bah MD, Bah I, Touré BM, Barry M, Kanté D, Bah OR, Diallo MB. La fistule urétro-cutanée après circoncision: analyse de 38 cas au CHU de Conakry, Guinee. Uro'Andro - Volume 1 Nº 7 Janvier 2017.

[9] Mouafo TFF, Ditope JJ, Fossi G, Fadi S, Nyanit BD, et al. Anatomic, Clinical and Therapeutic Aspects of Circumcision Accidents in Yaounde, Cameroon. Int Arch UrolComplic. 2016; 2:014.

[10] Bitho MS, Sylla S, Toure K, Akpo C, Boukary I, Mensah A, et al. Les accidents de la circoncision et de l'excision en mileu africain. Bull.Soc.Med. Afr. Noire Lang.Fr. 1975;20(3):249-55.

[11] Baskin LS, Canning DA, Snyder III HM, Duckett JW J. Surgical repair of urethral circumcision injuries. J.Urol. 1997; 158(6): 2269-71.

Citation: Kouka SCN, Diallo Y, Yonga D, Ouaimon DS, et al. Management of Urethrocutaneous Fistula Following Circumcision in Mbour Hospital, Senegal. Archives of Urology. 2020; 3(1): 01-04.

Copyright: (C) 2020 Kouka SCN, Diallo Y, Yonga D, Ouaimon DS, et al. This is an open access article distributed under the Creative Commons Attribution License, which permits unrestricted use, distribution, and reproduction in any medium, provided the original work is properly cited. 